\title{
In vitro and in vivo studies on biocompatibility of carbon fibres
}

\author{
Izabella Rajzer • Elzbieta Menaszek • \\ Lucie Bacakova $\cdot$ Monika Rom • Marta Blazewicz
}

Received: 7 February 2010/Accepted: 24 May 2010/Published online: 9 June 2010

(c) The Author(s) 2010. This article is published with open access at Springerlink.com

\begin{abstract}
In the present study we focused on the in vitro and in vivo evaluation of two types of carbon fibres (CFs): hydroxyapatite modified carbon fibres and porous carbon fibres. Porous CFs used as scaffold for tissues regeneration could simultaneously serve as a support for drug delivery or biologically active agents which would stimulate the tissue growth; while addition of nanohydroxyapatite to CFs precursor can modify their biological properties (such as bioactivity) without subsequent surface modifications, making the process cost and time effective. Presented results indicated that fibre modification with HAp promoted formation of apatite on the fibre surface during incubation in simulated body fluid. The materials biocompatibility was determined by culturing human osteoblast-like cells of the line MG 63 in contact with both types of CFs. Both tested materials gave good support to adhesion and growth of bone-derived cells. Materials were
\end{abstract}

\section{Rajzer $(\bowtie) \cdot$ M. Rom}

Faculty of Materials and Environmental Sciences, Institute of Textile Engineering and Polymer Science, Department of Polymer Materials, ATH University of Bielsko-Biala, Willowa 2, 43-309 Bielsko-Biała, Poland

e-mail: irajzer@ath.bielsko.pl

E. Menaszek

Collegium Medicum, Department of Cytobiology, UJ

Jagiellonian University, Medyczna 9, 30-068 Cracow, Poland

L. Bacakova

Academy of Sciences of the Czech Republic, Institute of Physiology, Videnska 1083, 14220 Prague 4-Krc, Czech Republic

E. Menaszek · M. Blazewicz

Faculty of Materials Science and Ceramics, Department of Biomaterials, AGH University of Science and Technology, Al. Mickiewicza 30, 30-059 Cracow, Poland implanted into the skeletal rat muscle and a comparative analysis of tissue reaction to the presence of the two types of CFs was done. Activities of marker metabolic enzymes: cytochrome c oxidase (CCO) and acid phosphatase were examined to estimate the effect of implants on the metabolic state of surrounding tissues. Presented results evidence the biocompatibility of porous CFs and activity that stimulates the growth of connective tissues. In case of CFs modified with hydroxyapatite the time of inflammatory reaction was shorter than in case of traditional CFs.

\section{Introduction}

Carbon fibres (CFs) have been widely investigated as potential constituents of medical devices for structural fixation of bone fragments, bone substitutes, cellular growth supports in tissue engineering etc. [1]. Biocompatibility of $\mathrm{CFs}$ has been the subject of numerous researches. Some of investigators concluded that $\mathrm{CFs}$ induce the growth of new tissue [2], however, there were also announcements questioning biocompatibility of CFs [3-5]. The different opinions regarding biocompatibility of CFs may be explained by the use of different types of CFs of different physical, structural and chemical properties, resulting from many technological parameters $[3,6]$. It has been demonstrated $[1,6,7]$ that the cellular response to the fibrous carbon material depends on the degree of crystallinity of the material; therefore only selected types of CFs are suitable for tissue treatment purposes.

Carbon fibres have been used in the reconstruction of parallel-fibred tissue such as ligaments and tendons. They induce proliferation of ordered collagenous fibrous tissue in the direction of the carbon fibre filaments [2, 8]. Various fibrous forms of carbon materials have been also tested for 
repairing of hard and soft injuries [6,9] such as hernia repair [10] to fill the tissue losses of rabbit's cartilages [11] as well as in bone defect treatment [9]. Beside CFs were widely applicable in composite materials for medicine. The use of $\mathrm{CFs}$ as the modifying phase increase the strength of the polymer/carbon composite and the fibres uncovered after polymer resorption process can serve as the scaffold for bone tissue regeneration [12]. Composite carbon biomaterials have been also used in orthopedics to manufacture plates [13], screws [14] and elements of external stabilizers for osteosynthesis, hip joint endoprostheses [15] and also some types of medical equipment [16, 17]. Controlled modification of the surface of carbon biomaterials can change the effect or function of immunological cells response [7].

Research on CFs coated with a layer of pyrolytic carbon indicated that such implants have stimulated tissue regeneration [9].

Carbon fibres are biocompatible even though they are not bioactive in an extent comparable to properties of bioglasses or bioceramics [18], so that modification of CFs' surface with ceramic particles such as hydroxyapatite (HAp) is increasingly practiced $[19,20]$.

It is well know that HAp binds with the bone by the bone-like apatite layer which is formed in biological environment on the HAp surface [21]. It is believed that formation of apatite leads to chemical bonding on the implant-bone interface [22].

The primary objective of this study was the biological evaluation of two types of new CFs which are perspective to be used for creation of three-dimensional scaffolds for tissue engineering. Among the possible forms of implants, fibrous matrices are highly promising for the tissue regeneration by acting as a cell-supporting scaffold. It may be expected that application of carbon fabrics composed of porous fibres or fibres modified with HAp nanoparticles would have regenerative potential in the treatment of bone diseases. Porous carbon fibre used as scaffold for tissues regeneration could simultaneously serve as a support for drug delivery or biologically active agents which would stimulate the tissue growth; while addition of nanohydroxyapatite to CFs precursor can modify their biological properties without subsequent surface modifications, making the process cost and time effective. Therefore, in this study, we investigated the behaviour of porous and nanoHAp-modified CFs in biological environments and their interaction with cells and tissues under in vitro and in vivo conditions.

\section{Materials and methods}

For these investigation porous polyacrylonitrile (PAN) fibres and fibres containing nanohydroxyapatite (HAp) prepared at the Technical University of Lódź were selected. Fibres were obtained using PAN-terpolymer from Zoltek (Hungary) of the following composition: $93-94 \%$ of weight meres of acrylonitrile, 5-6\% of weight meres of methyl acrylate and about $1 \%$ of weight meres of alilosulphoniane. Dimethylformamide (DMF) was used as a solvent. Hydroxyapatite (HAp) used in the study was provided by the University of Science and Technology (Cracow, Poland) [23]. The specific surface area of the HAp powder was $71.4 \mathrm{~m}^{2} / \mathrm{g}$. HAp $(3 \% \mathrm{w} / \mathrm{w})$ were added to PAN spinning solution. Porous fibres as well as fibres with and without HAp powder were spun as described elsewhere [24, 25].

Carbon fibres used in this study were prepared by thermal treatment of three types of PAN precursor fibres via two-stage process, starting from thermal treatment in air atmosphere at $150-280^{\circ} \mathrm{C}$ followed by carbonization in an atmosphere of pure argon at $1,000^{\circ} \mathrm{C}$. Details of the thermal transformation of the PAN precursor fibres into CFs are given in previous works [26]. The average diameter of the fibres after carbonization process was $10 \mu \mathrm{m}$.

Three following different types of fibres were selected:

(1) Porous carbon fibres (CF/P)

(2) Carbon fibres modified with hydroxyapatite ( $\mathrm{CF} / \mathrm{HAp})$

(3) Carbon fibres-standard, not modified ( $\mathrm{CF} / \mathrm{T})$

Microstructure and chemical composition of CFs were characterized using scanning electron microscopes: NOVA NANO SEM 200, FEJ EUROPE COMPANY, Jeol, JSM5500 and Jeol, JSM-5400 equipped with EDS Link ISIS 300 device for chemical analysis of micro-areas.

\subsection{In vitro bioactivity testing in SBF}

Carbon fibres modified with HAp (CF/HAp) and reference standard non-modified carbon fibres $(\mathrm{CF} / \mathrm{T})$ were incubated for 20 days in $50 \mathrm{ml}$ of simulated body fluid (SBF) $(\mathrm{pH}$ $7.4 ; 37^{\circ} \mathrm{C}$ ), in closed polyethylene containers. SBF solution, also referred as artificial blood plasma, was prepared according to the procedure described by Kokubo [27]. The SBF solutions were collected for determination of calcium (Ca) and phosphorous $(\mathrm{P})$ ion concentration changes by inductively coupled plasma atomic emission spectroscopy (ICP-AES, PLASMA 40, Perkin Elmer). After 20 days the samples were separated, rinsed with water and dried at room temperature. Surface morphology before and after incubation in artificial plasma (SBF) was evaluated using scanning electron microscopy (SEM, Jeol JSM-5400).

\subsection{Cell culture}

In vitro tests in cell cultures were performed in the Institute of Physiology, Academy of Sciences of the Czech Republic, 
Prague. Prior to the analysis, bunches of $\mathrm{CF} / \mathrm{HAp}, \mathrm{CF} / \mathrm{P}$ and $\mathrm{CF} / \mathrm{T}$ fibres were subjected to thermal sterilization at the temperature of $160^{\circ} \mathrm{C}$ for $120 \mathrm{~min}$.

For testing the cell-material interaction in vitro, human osteoblast-like MG-63 cells (European Collection of Cell Cultures, Salisbury, UK) were used. Although these cells were derived from osteosarcoma, they retained important markers of osteogenic cell differentiation, such as the activity of alkaline phosphatase and production osteocalcin, thus they can serve as a good in vitro model for testing the compatibility of various materials with bone cells [28]. Fibrous samples were inserted into polystyrene multidishes (24 wells, diameter $15 \mathrm{~mm}$, TPP Company, Trasadingen, Switzerland), and seeded with MG-63 cells. Each well contained 10 fibres (each $1 \mathrm{~cm}$ long), 50,000 cells/well and $1.5 \mathrm{ml}$ of Dulbecco's Modified Eagle Medium supplemented with $10 \%$ of fetal bovine serum and gentamicin $(40 \mu \mathrm{g} / \mathrm{ml})$. Conventional cell culture support, i.e. the bottom of polystyrene dishes served as a control material. Cells were incubated at $37^{\circ} \mathrm{C}$ in air atmosphere with $5 \%$ $\mathrm{CO}_{2}$. After 1, 3 and 7 days of incubation, the samples were rinsed in phosphate-buffered saline (PBS), fixed in $70 \%$ cold ethanol $\left(-20^{\circ} \mathrm{C}, 5 \mathrm{~min}\right)$, visualized by staining with propidium iodide (concentration $5 \mu \mathrm{g} / \mathrm{ml}$ in PBS, incubation $5 \mathrm{~min}$ at room temperature), and their morphology and distribution was evaluated and documented using epifluorescence microscope IX 51 equipped with a digital camera DP 70 (Olympus, Japan).

Effects of the tested materials on the adhesion, growth and morphology of cells on the fibres as well as on the underlying well bottom were evaluated. For separate counting of cell number on the fibres and on the well bottoms, the fibres were carefully moved to fresh wells without their damage or cell detachment. Both groups of cells were then rinsed in PBS and exposed to $0.1 \%$ trypsin solution in PBS ( $\mathrm{pH} 7.35$, temperature $37^{\circ} \mathrm{C}, 5 \mathrm{~min}$ ) in order to release the cells from the materials. Cells were counted in a Burker's hemocytometer using an inverted optical microscope (Olympus IX 51). Statistical significance of the differences between the experimental groups was estimated using ANOVA, Student-Newman-Keuls method.

\subsection{In vivo study}

The rat skeletal muscle was used as model tissue for in vivo studies, due to the composition of the muscle, which apart from striated muscle cells contains also nerve fibres, connective tissue and blood vessels. The cell response of soft tissues to the synthetic implanted material is more intensive and processes of soft tissue regeneration are more difficult. Moreover, in clinical practice, the probability of contact of the material used for filling bone loses with surrounding tissues including muscles is high.
The experiment was performed according to the EU ISO 10993-6 guidelines and the study protocol was approved by the I Local Bioethics Committee in Cracow, Poland (No. 32/2003).

Carbon fibres $(\mathrm{CF} / \mathrm{HAp}, \mathrm{CF} / \mathrm{P})$ used in the experiment were sterilized in a dry hot air sterilizer in $160^{\circ} \mathrm{C} / 120 \mathrm{~min}$. Next they were implanted under sterile conditions into the gluteus muscle of 20 adult male Hooded Oxford (HO/Krf) inbred rats. Animals were anesthetized with pentobarbitalum (Vetbutal, Biowet Puławy, Poland). Skin in the site of surgery was shaved and disinfected, and a small incision was made to create a $4 \mathrm{~mm}$ deep pouch in the gluteus muscle. Equal portions $(10 \mathrm{mg})$ of the $\mathrm{CFs}$ were inserted into the pouch. The muscle and skin wounds were closed with 5/0 PDS II (polydioxanone) monofilament absorbable sutures (Ethicon Ltd., UK). All animals survived the surgery. No wound healing complications were observed after the surgery and during the whole experiment. The animals were maintained under standard conditions with free access to food and water.

After 7, 30, 90, 150 and 210 days from the surgery, at each time point 4 animals were sacrificed with an overdose of Vetbutal. Tissue specimens containing the implanted material were excised and immediately frozen in liquid nitrogen. Next they were cut into $8 \mu \mathrm{m}$ thick slides in a Pearse-Slee cryostat at $-22^{\circ} \mathrm{C}$. In order to estimate the processes of tissue regeneration and the tissue-implant interface, the obtained slides were examined by histological and histochemical reactions.

The metabolic state of tissues surrounding the implants was estimated by measuring activities of the following enzymes: cytochrome c oxidase (CCO), and glucose-6phosphate dehydrogenase. The relative number of inflammatory cells revealed by May-Grünwald-Giemsa method and the activity of a hydrolytic enzyme-acid phosphatase-were used to assess the extent of inflammation around the implant. The presence and thickness of fibrous capsule was assessed on slides stained by Van Gieson's method.

Observations were made using an optical microscope BX (Olympus, Germany), and pictures were taken with a digital camera CAMEDIA (Olympus, Germany).

\section{Results}

Microstructure of materials used in this study can be observed in Figs. 1 and 2. Particles (nanoparticle agglomerates) of calcium phosphate are clearly visible on the $\mathrm{CF} /$ HAp fibres surface (Fig. 1). Elongated pores of various sizes were found on the surface of CF/P fibres (Fig. 2). The analysis of the fibres cross-section shows that the pores occurred at the outer layer of the fibres and formed irregular channels along the fibre axis. 

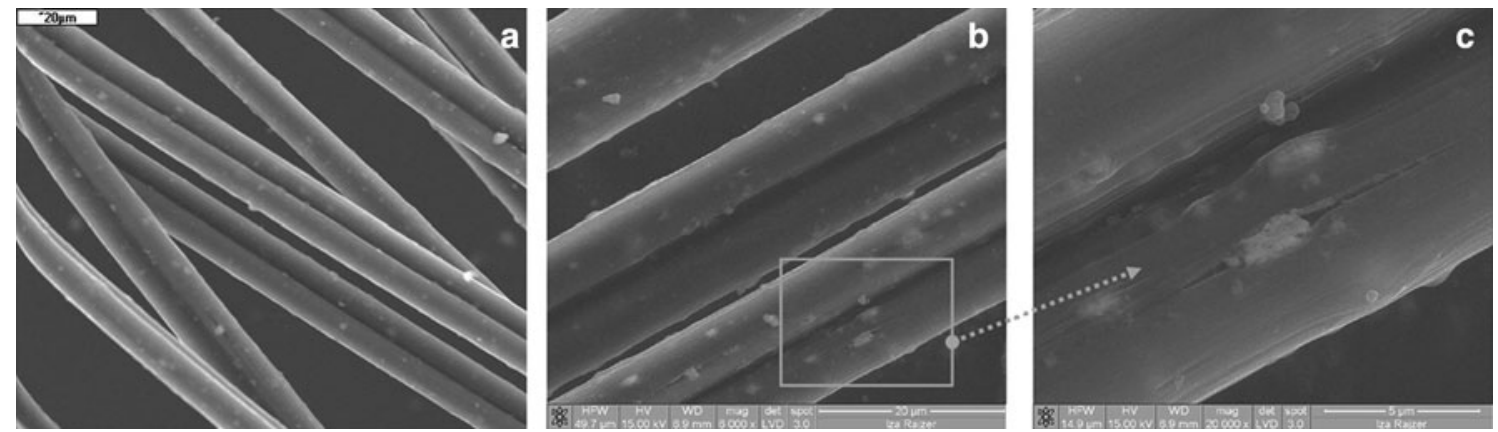

Fig. 1 Scanning electron microscope (Jeol, JSM-5400, NOVA NANO SEM 200, FEJ EUROPE COMPANY) images of CFs with HAp particles (CF/HAp): a magnification $1000 \times$, bar $=20 \mu \mathrm{m}$; b magnification $6000 \times$, bar $=20 \mu \mathrm{m}$ and $\mathbf{c}$ magnification $20000 \times$, bar $=5 \mu \mathrm{m}$
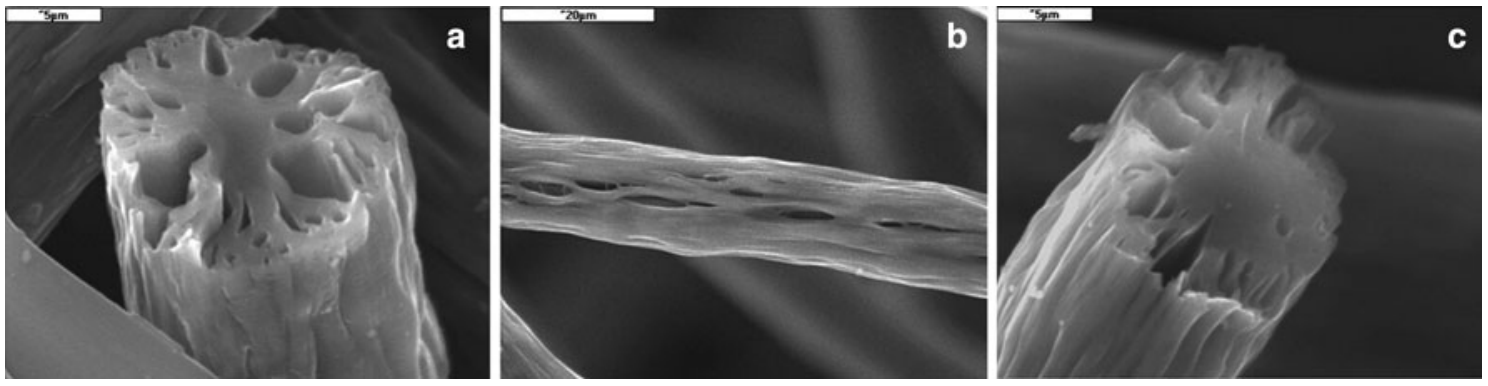

Fig. 2 Scanning electron microscope (Jeol, JSM-5400) images of porous carbon fibres CF/P: a magnification $7000 \times$, bar $=5 \mu$ m; b magnification $2500 \times$, bar $=20 \mu \mathrm{m}$ and $\mathbf{c}$ magnification $7000 \times$, bar $=5 \mu \mathrm{m}$

\subsection{In vitro bioactivity tests in SBF}

The surface of HAp modified carbon fibres (CF/HAp) before incubation in SBF was relatively smooth with small and sporadic prominences on the material surface (Fig. 3a). During the incubation in SBF, the character of the fibre surface has been markedly changed by abundant deposits (Fig. 3b, c), which were then analyzed by EDS method (Fig. 4). EDS analysis indicated the presence of oxygen, phosphorous and calcium ions on the surface suggested the presence of a newly formed apatite on the $\mathrm{CF} / \mathrm{HAp}$ surface.

Changes of ion concentration in SBF solution during $\mathrm{CF} / \mathrm{HAp}$ incubation are presented in Fig. 4c. In contrast to slowly increasing concentration of $\mathrm{Ca}$ ions, the concentration of $\mathrm{P}$ ions in SBF gradually decreases. Formation of $\mathrm{Ca}-\mathrm{P}$ layer on the fibres surface is dependent on absorption of $\mathrm{Ca}$ ions from the solution, simultaneously the hydroxyapatite embedded in fibres is gradually solubilized and calcium ions are liberated. Based on Fig. $4 \mathrm{c}$ it can be supposed that more ions were released from fibres than absorbed from solution, so that the slight increase of calcium ion concentration is observed. On the other hand decreased concentration of phosphorus ions in SBF solution can be assigned to $\mathrm{P}$ ions consumption needed to formation of apatite layer. Obtained results support the statement that when calcium phosphate in organic matrix is heated up to $1,000^{\circ} \mathrm{C}$, it decomposes, and as a result of
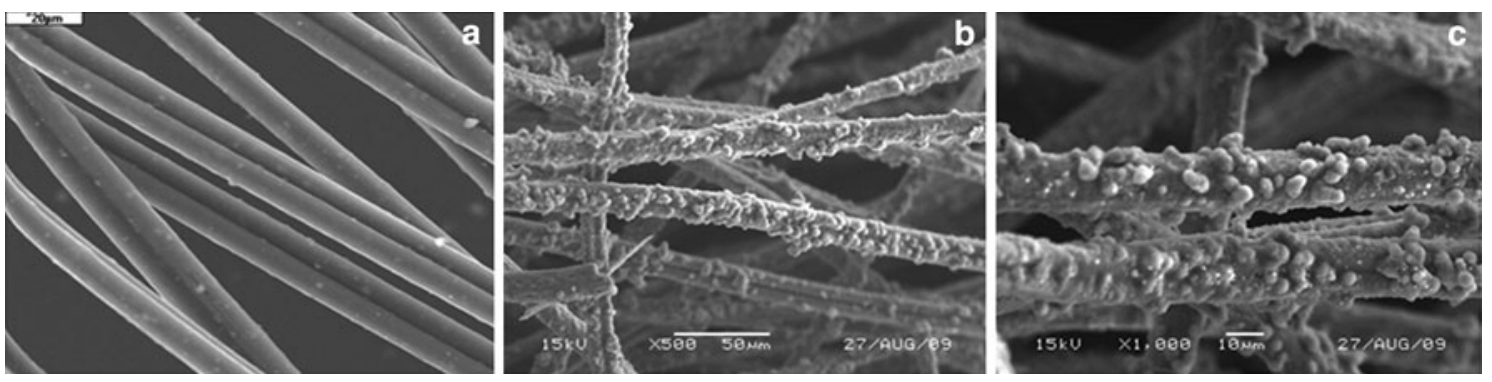

Fig. 3 CF/HAp surfaces before (a) and after (b, c) immersion in SBF. Scanning electron microscope (Jeol, JSM-5400; Jeol, JSM-5500): a magnification $1000 \times$, bar $=20 \mu \mathrm{m}$; b magnification $1000 \times$, bar $50=\mu \mathrm{m}$, and $\mathbf{c}$ magnification $1000 \times$, bar $=10 \mu \mathrm{m}$ 

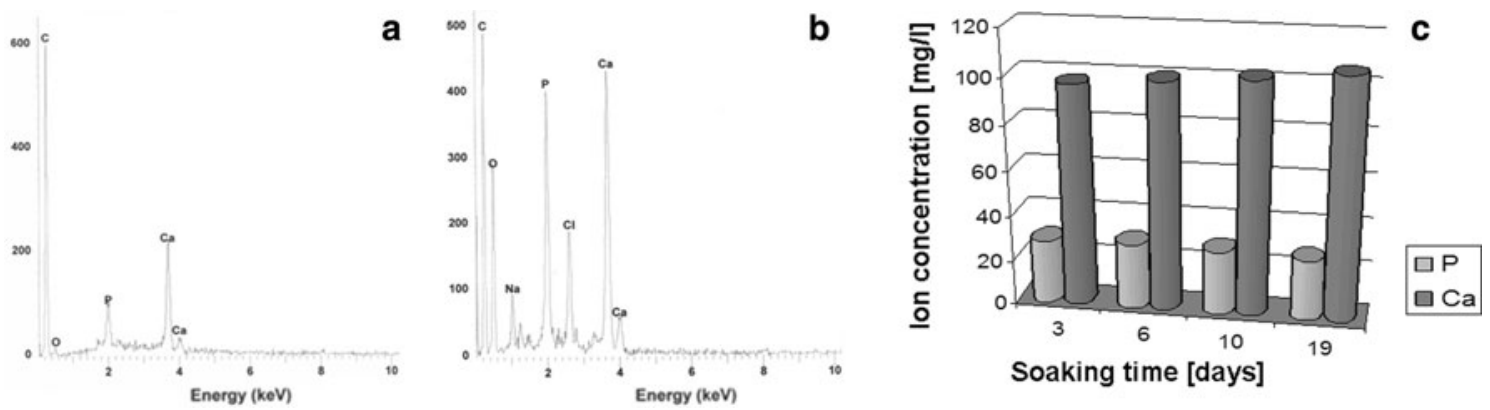

Fig. 4 EDS analysis for CF/HAp fibres before (a) and after (b) immersion in SBF, (c) changes of ion concentration in SBF solution during immersion of $\mathrm{CF} / \mathrm{HAp}$ fibres in $\mathrm{SBF}$

decomposition soluble fraction appears, which can be then solubilized in SBF solution and can foster phosphate crystallization on the fibre surface.

\subsection{Adhesion and proliferation of osteoblast-like cells} on HAp modified and porous CFs

The numbers of cells colonizing the surface of $\mathrm{CF} / \mathrm{HAp}$, $\mathrm{CF} / \mathrm{P}$ or $\mathrm{CF} / \mathrm{T}$ fibres and the underlying bottom of the culture wells on 1, 3 and 7 days after seeding are presented in Fig. 5.

In 1-day-old cultures, most cells seeded into wells with CFs adhered to the underlying well bottom. Only approx. $11,000-25,000$ of cells were retained on the fibres, which was probably due to their narrow, elongated shape and thus a relatively small effective area utilized for the cell adhesion. The highest number of initially attached cells was found on CFs modified with HAp, i.e. containing prominences on their surface, while smooth fibre surfaces $(\mathrm{CF} / \mathrm{T})$ hindered the cell attachment in the greatest extent. However, similarly as in our earlier study performed on carbon-

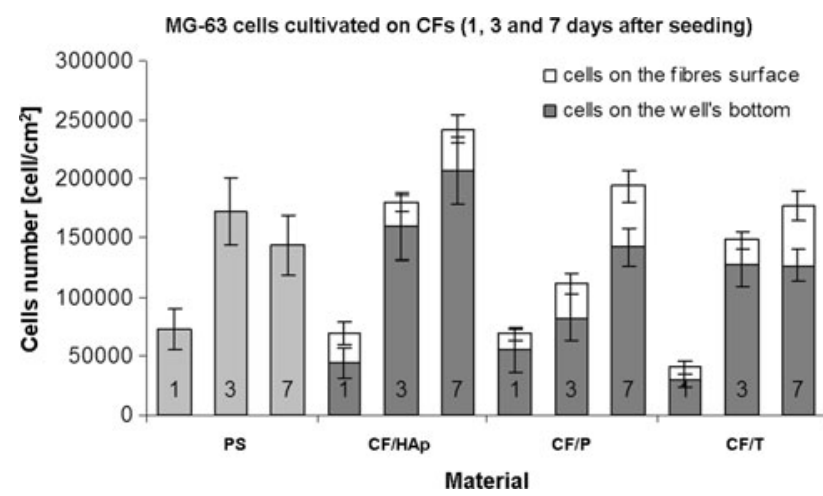

Fig. 5 The correlation among the numbers of MG-63 cells adhering and growing on various types of $\mathrm{CFs}$ and on the underlying well bottoms on days 1,3 , and 7 after seeding. PS: standard polystyrene cell culture well without fibres, CF/HAp: carbon fibres modified with hydroxyapatite, $\mathrm{CF} / \mathrm{P}$ : porous carbon fibres or $\mathrm{CF} / \mathrm{T}$ : standard carbon fibres. Mean \pm SEM from 4 to 12 measurements, ANOVA StudentNewman-Keuls method carbon composites [29] prominences on the material surface might hamper the subsequent cell proliferation. On day 3 after seeding, the cell number on $\mathrm{CF} / \mathrm{HAp}$ fibres was in average even lower than on day 1 , and on day 7 , the cells on these fibres attained a lower final cell population density than on $\mathrm{CF} / \mathrm{P}$ and $\mathrm{CF} / \mathrm{T}$ fibres.

However, on the well bottom underlying the CF/HAp fibres, the cells proliferated better than in wells with the other types of CFs, and on day 7 after seeding, their population density exceeded the value in control wells without fibres. A possible explanation is that HAp on the fibres might release bioactive ions, such as $\mathrm{Ca}$ or $\mathrm{P}$, which supported the cell growth. Similarly, HAp islets deposited on titanium-based composite materials partially dissolved in the cell culture medium, which was associated with high proliferation and alkaline phosphatase activity of osteoblastic SaOs-2 cells cultured in contact with these materials [30]. Also ionic products of dicalcium silicate $\left(\mathrm{Ca}_{2} \mathrm{SiO}_{4}\right)$ coating, dissolved in the cell culture medium, enhanced the proliferation activity and gene expression of bone differentiation markers (i.e., alkaline phosphatase and osteocalcin) in MG 63 cells [28].

Results of observations of the morphology of cells seeded on the surface of porous carbon fibres (CF/P) and on the surface of fibres modified with HAp (CF/HAp) are presented in Figs. 6 and 7 consequently. Morphology of cells observed on both types of fibres is very similar to the morphology of cells incubated on control PS surface, i.e. cells of both groups are mostly spindle-shaped (Fig. 6a). Observed cells are uniformly spread along fibres and cover almost all their surface. Such a spreading of cells indicates the good adhesion.

Taken together, cell counting and fluorescence microscopy observations confirmed good biocompatibility of CFs, which is substantiated with both consecutively increasing number of cells from day 1 to 7 after seeding and good spreading of cells along the fibre surface. The highest initial adhesion of cells was found on CF/HAp fibres, but the subsequent proliferation was more pronounced on $\mathrm{CF} / \mathrm{P}$ and $\mathrm{CF} / \mathrm{T}$ fibres. Nevertheless, the $\mathrm{CF} / \mathrm{HAp}$ fibres 

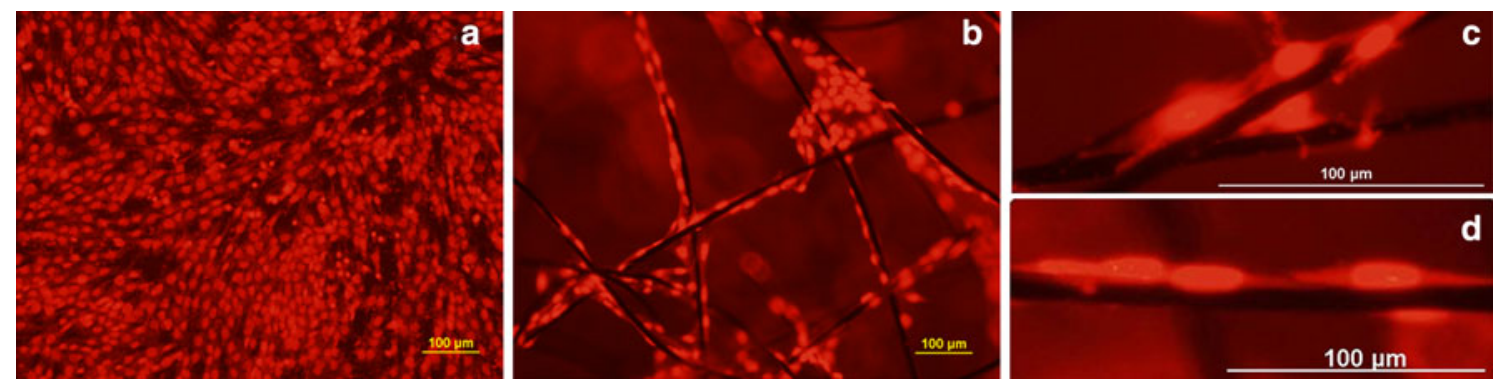

Fig. 6 Morphology of MG-63 cells seeded on porous CF/P fibres after 7 days in culture: a cells on control PS plate and b-d cells on porous $\mathrm{CF} / \mathrm{P}$ fibres. Stained with propidium iodide, microscope Olympus IX 51, digital camera DP 70, obj. 20×, bar $=100 \mu \mathrm{m}$
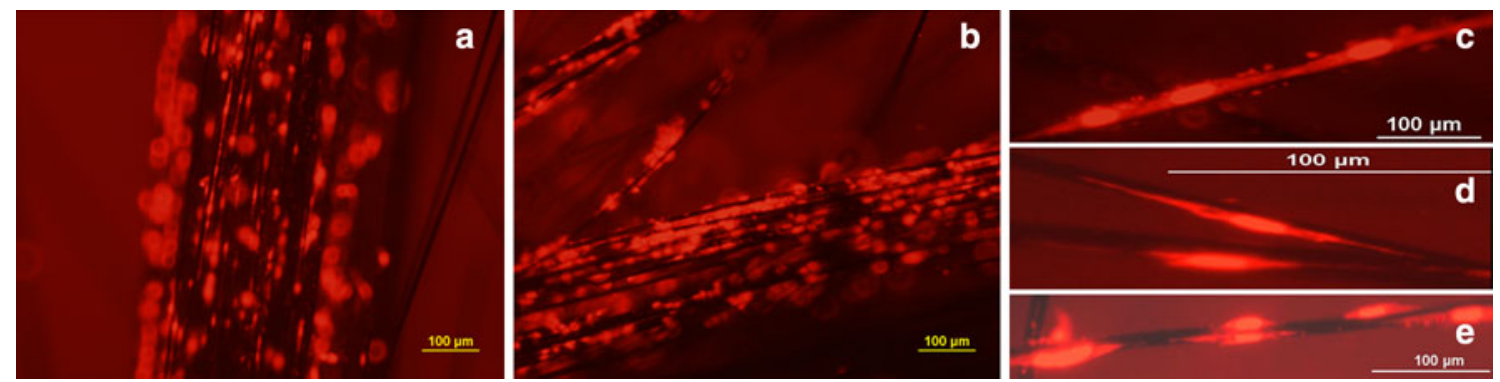

Fig. 7 Morphology of osteoblast-like MG-63 cells incubated on CF/HAp fibres after 7 days in culture. Stained with propidium iodide, microscope Olympus IX 51, digital camera DP 70, obj. $20 \times$, bar $=100 \mu \mathrm{m}$

stimulated in the greatest extent the proliferation of cells on the underlying well bottom.

\subsection{In vivo tests}

\subsubsection{Histological studies}

Cutting of samples extracted from the site of implantation together with the surrounding tissue were subjected to histological tests. Parameters such as intensity of inflammation process in tissues surrounding implanted fibres, the thickness of connective tissue formed around the implant, progress of regeneration process as well as the effect of the presence of CF fibre fragments (i.e. products of degradation) on the process of tissue regeneration were evaluated.

Seven days after implantation, neutrophils and eosinophils were observed around the implanted fibres. The presence of cells responsible for combating infections provides the information on the inflammatory infiltration, associated with both the presence of foreign body (i.e., $\mathrm{CFs}$ ) and the tissue injury as an effect of the implantation. Neutrophils are the main cell types observed at early stages of inflammations. They are directed into implantation place in order to neutralize the injury and to prepare the tissue to the self-reparation, so that their presence is indispensable to start wound healing process.

An important finding was that different types of CFs evoked a different response of the surrounding tissue on day 7 after implantation. An extensive inflammatory exudate was observed in case of fibres modified with HAp (CF/HAp) (Fig. 8a) The presence of neutrophils evidenced an acute inflammation.

In case of $\mathrm{CF} / \mathrm{P}$ implant, the area of implantation was narrow and surrounded with cells (Fig. 9a). Numerous eosinophils were present; however no neutrophils were observed. At early stages of inflammation the role of eosinophils is similar to the role of neutrophils, that is they eliminate and englobe inflammation factors, and on the later stages of wound healing they provide additional growth factors. Along with mast cells, the eosinophils also are important mediators of allergic responses. After 7 days from implantation of $\mathrm{CF} / \mathrm{P}$ fibres, the stage of acute inflammation is finished, self-reparation takes place and mast cells plays an essential role in regeneration processes. Mast cells release chemical compounds (e.g. chemoattractants and proteinases) enabling other cells of immune system to reach the place of injury. Moreover they take part in angiogenesis and processes of tissue repair, affecting proliferation of fibroblasts. In both cases the inflammatory processes were not sustained.

After 30 days from implantation, differences in tissue response to both types of implanted materials were more pronounced (Figs. 8b, 9b). In the case of fibres modified with HAp, the observed implant is agglomerated and surrounded with granulation tissue. In both kinds of implants, foreign body-type multinucleated giant cells were observed 

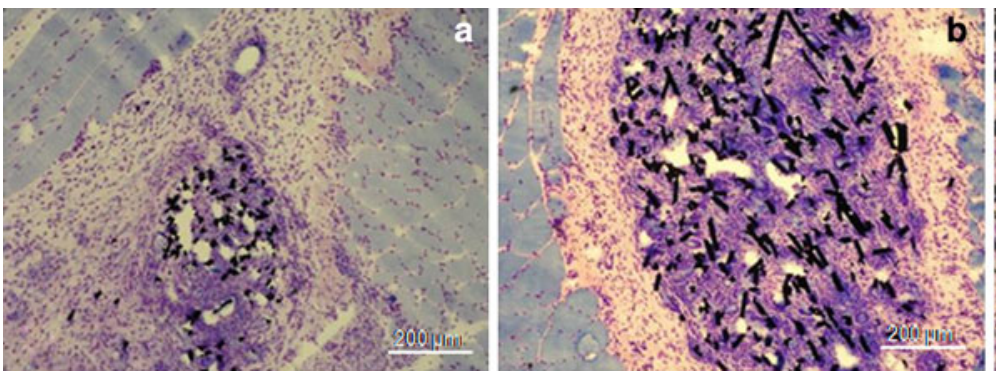

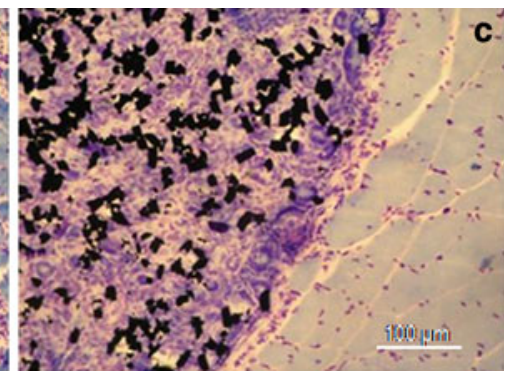

after 210 days (obj. $20 \times$, bar $=100 \mu \mathrm{m}$ ). Microscope Olympus BX 51, digital camera CAMEDIA; staining according to Pappenheim

According to Van Gieson method as the effect of staining collagen fibres are getting red and muscles are getting yellow. Implantation sites 1 week after surgery are presented in Figs. 10a and 11a.

Collagen layer visible on the border of muscle tissue and infiltration surrounded both types of implanted fibres in a similar way. Within the region of infiltration, also loosely dislocated collagen fibres were apparent. During the first weeks after surgery, the site of implantation was embedded with connective tissue capsule, and thus isolated from the surrounding tissues. The thickness of capsule was decreasing over time and finally it reached the dimensions comparable with the spacing between muscle fibres.
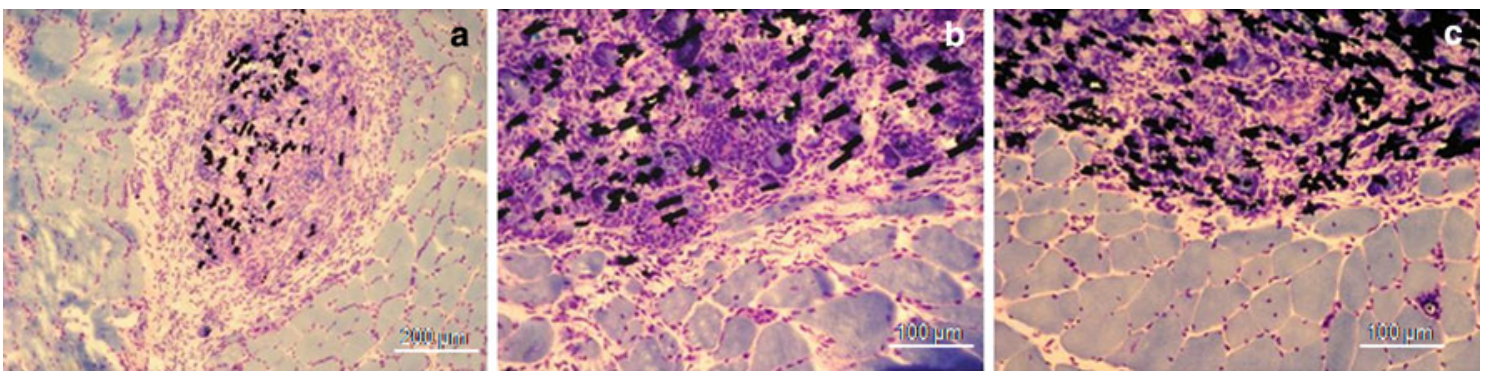

Fig. 9 Cross-section of rat skeletal muscle with implanted carbon fibres $(\mathrm{CF} / \mathrm{P})$ a after 7 days from implantation (obj. 10×, bar $=200 \mu \mathrm{m})$; b after 30 days $($ obj. $20 \times$, bar $=100 \mu \mathrm{m})$ and $\mathbf{c}$ after 210 days (obj. $20 \times$, bar $=100 \mu \mathrm{m}$ ). Microscope Olympus BX 51, digital camera CAMEDIA; staining according to Pappenheim
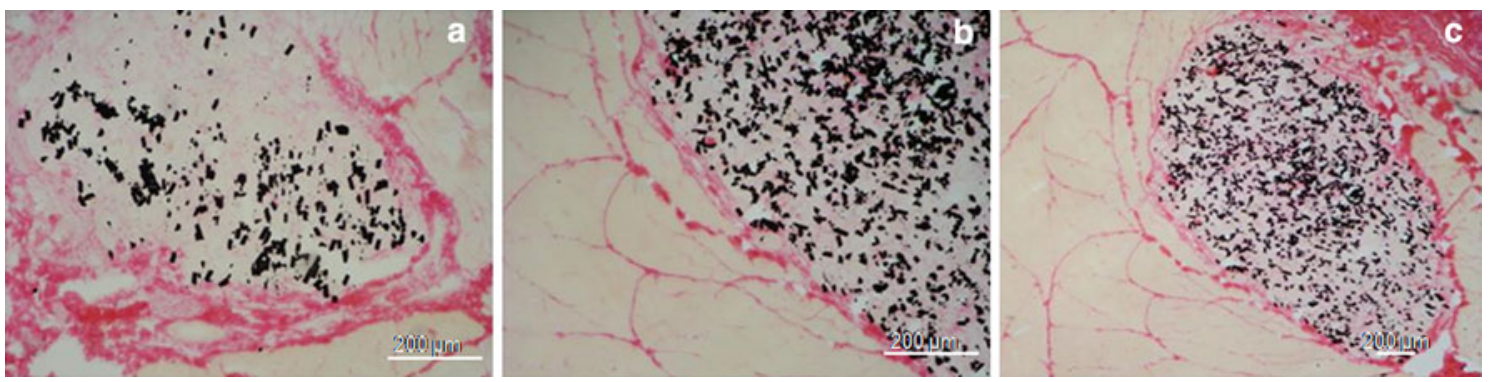

Fig. 10 Cross-section of rat skeletal muscle with implanted CF/HAp fibres a after 7 days (obj. $10 \times$ ); b after 210 days (obj. $10 \times$ ) and $\mathbf{c}$ after 210 days $($ obj. $4 \times$ ); bar $=200 \mu \mathrm{m}$. Microscope Olympus BX 51, digital camera CAMEDIA; Collagen fibres surrounding the implant are stained according to Van Gieson protocol 

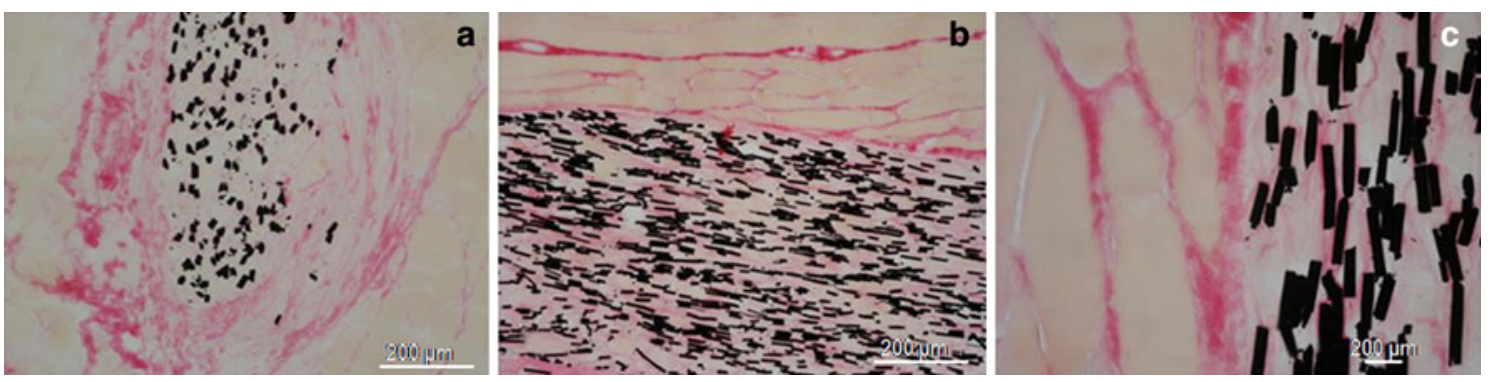

Fig. 11 Cross-section of rat skeletal muscle with implanted CF/P fibres: a after 7 days (obj. 10×); b after 210 days (obj. 10×) and $\mathbf{c}$ after 210 days $($ obj. $4 \times$ ), bar $=200 \mu \mathrm{m}$. Microscope Olympus BX 51, digital camera CAMEDIA; Staining according to Van Gieson protocol

\subsubsection{Histochemical analysis}

The effect of implanted CFs on the metabolic state of surrounding tissues as well as tissues growing into the region of implants was analyzed using histochemical methods. Those methods enable tracing changes in the activity of enzymes specific for particular stages of the inflammatory process observed directly after implantation, and then during wound healing process. Activity of $\mathrm{CCO}$ and acid phosphatase was analyzed. Selected enzymes are particularly important for regular metabolism. CCO present in mitochondrions is responsible for cellular respiration and controls the transport of electrons. Acid phosphatase, being a hydrolytic enzyme present in lysosomes (mostly in phagocytes), enables decomposition of metabolites. Based on mentioned above enzymes activities it is possible to conclude on the advancement of the inflammatory process.

\subsection{Acid phosphatase activity}

Acid phosphatase activity provide information regarding intensity of inflammatory process, however it is very difficult to estimate changes of acid phosphatase activity on the rat skeletal muscle sections. The reaction of acid phosphatase in the regions with $\mathrm{CF} / \mathrm{P}$ and $\mathrm{CF} / \mathrm{HAp}$ fibres 30 days after implantation is presented in Fig. 12. Both macrophages and multinucleated giant cells with high enzymatic activities are visible in surroundings of CFs.

\subsection{Cytochrome c oxidase analysis}

In case of histoenzymatically regular rat skeletal muscle, it is possible to distinguish three types of skeletal muscles organized in mosaic form visible on the muscle cross-section. Taking into account activity of oxidizing enzymes present in muscles, it may be stated that the activity is higher in case of thinner fibres, and lower in case of thicker ones. Beside thick and thin fibres, fibres which morphology and enzymatic activity in an intermediate state are also present in the muscle. Using histochemical methods it is possible to provide information regarding changes of enzymatical activity of muscle fibres such as dysregulation of mosaic structure, lack of fibres diversity, lack or decrease of enzymatic activity or unequal enzymatic activity within fibres cross-section.
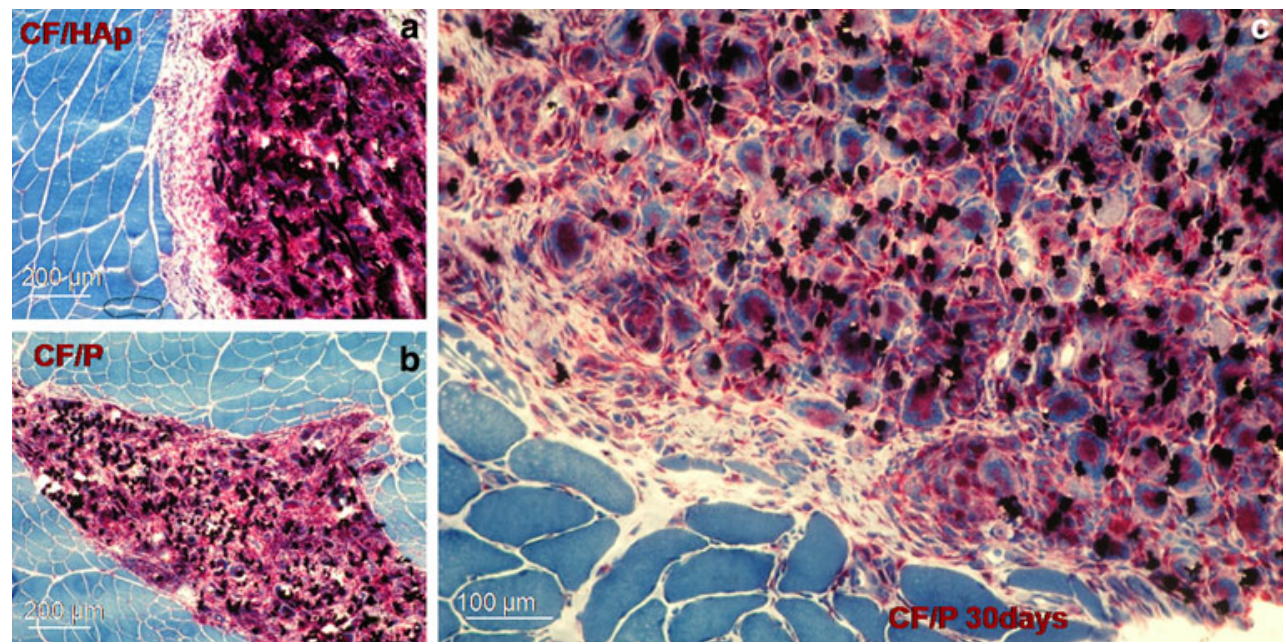

Fig. 12 Cross-section of rat's skeletal muscle. Acid phosphatase activity against a CF/HAp fibres and (b-c) CF/P after 30 days. Microscope Olympus BX 51, digital camera CAMEDIA; obj. $10 \times$, bar $=200 \mu \mathrm{m}$, obj. $20 \times$, bar $=100 \mu \mathrm{m}$ 
Cytochrome $\mathrm{c}$ oxidase activity provides information on metabolism of rat skeletal muscles tissue surrounding the implant. The effect of implantation of $\mathrm{CF} / \mathrm{HAp}$ and $\mathrm{CF} / \mathrm{P}$ on the CCO activity is presented in Figs. 13 and 14. Regenerative processes were observed just after 7 days from implantation (Fig. 13a). Fine blood vessels were observed within granulation tissue growing into the implanted materials and the regenerated muscle fibres appeared on the border between injured tissue and implanted material. In subsequent streams of samples granulation tissue within the implant was replaced by such regenerated muscle fibres. Biocompatibility of implanted materials can be substantiated by the lack of connective tissue capsule surrounding the implanted biomaterial (Figs. 13c, d, 14a-c) and by the regenerating muscle cells growing within the structure of implant. Moreover the direct contact between implanted CFs and muscle tissues was observed in numerous places; and both mosaic structure of fibres and enzymatic activity remained unaltered.

\section{Discussion}

The assumption that carbon as the fundamental element in biological tissues would not induce adverse reactions encouraged scientists to use carbon fibers in medicine as the implantable biomaterial [1]. In the field of regenerative medicine carbon materials are becoming increasingly attractive as they can be modified to be integrated into human bodies for promotion of tissue regeneration and treatment of various diseases.

Properties of CFs important for medical applications are related to the physical and chemical structure of their surface, as well as to the broad possibility of customize of their mechanical properties, so that the fibers' properties should be comparable with the tissues replaced. Based on microscopic observations we have confirmed that adhesion of cells to porous fibers which were of highest accessible surface within analyzed samples was much better than in case of the other types of analyzed fibers. According to in vivo studies, $\mathrm{CF} / \mathrm{P}$ fibers due to their significant porosity enable more efficient growing of cells and connective tissue within the structure of implant.

Biocompatibility of $\mathrm{CFs}$ has been the subject of numerous researches, however individual researchers implemented it in their own experiments without further physical and chemical characterization, and also without specifying the sterilization methods, so that cases of toxic effects of fiber degradation products on the human body were also reported [31-33]. CF in many cases were well tolerated by the recipient and did not cause the around foreign body reactions [6]. Moreover the tendon or
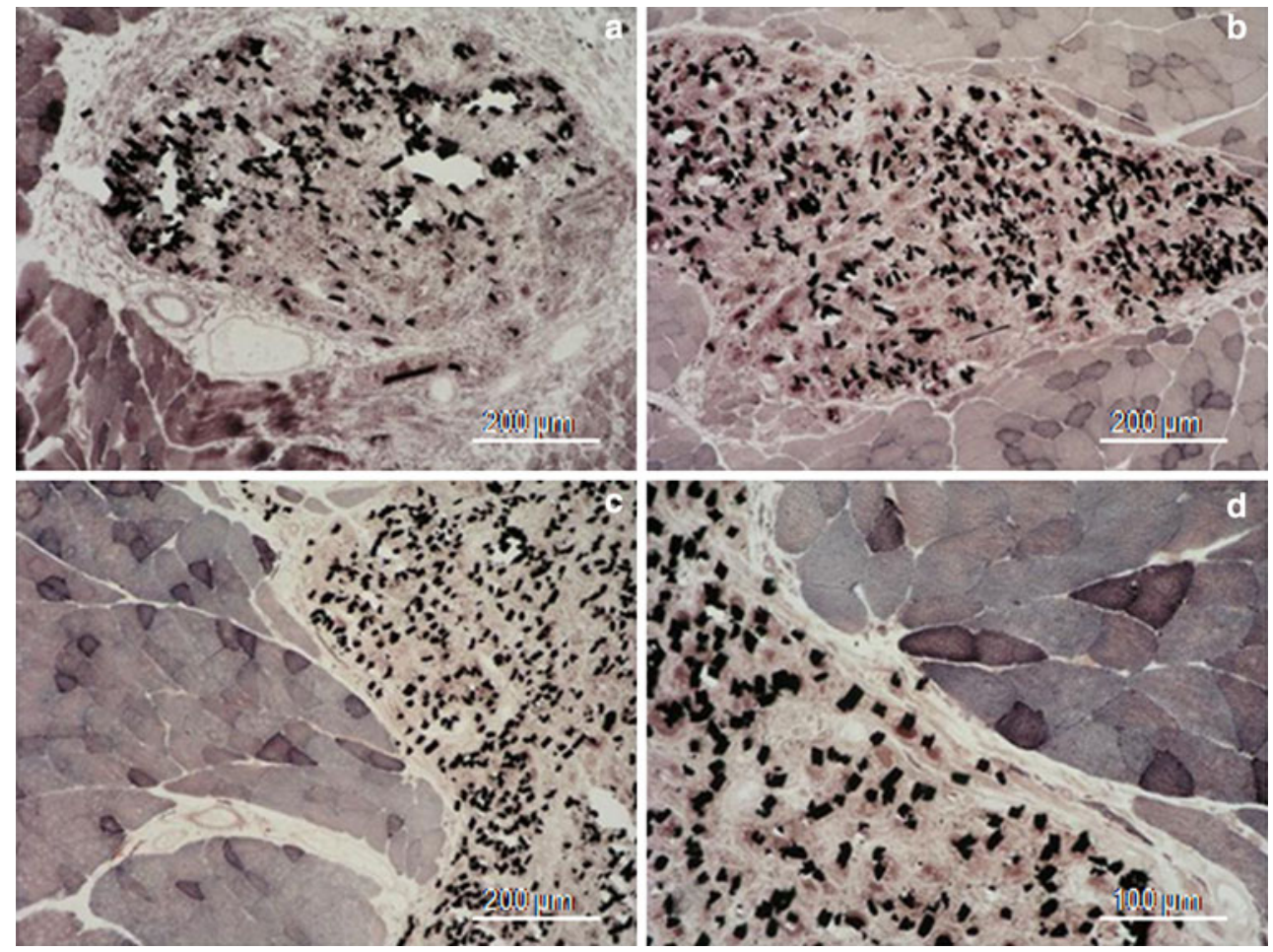

Fig. 13 Cytochrome c oxidase activity on a cross-section of rat skeletal muscle implanted with $\mathrm{CF} / \mathrm{HAp}$ fibres a after 7 days, $\mathbf{b}$ after 90 days (obj. $10 \times$, bar $=200 \mu \mathrm{m}$ ); c-d after 210 days (obj. $10 \times$,

bar $=200 \mu \mathrm{m}$; obj. $20 \times$, bar $=100 \mu \mathrm{m}$ ); Microscope Olympus BX 51, digital camera CAMEDIA 


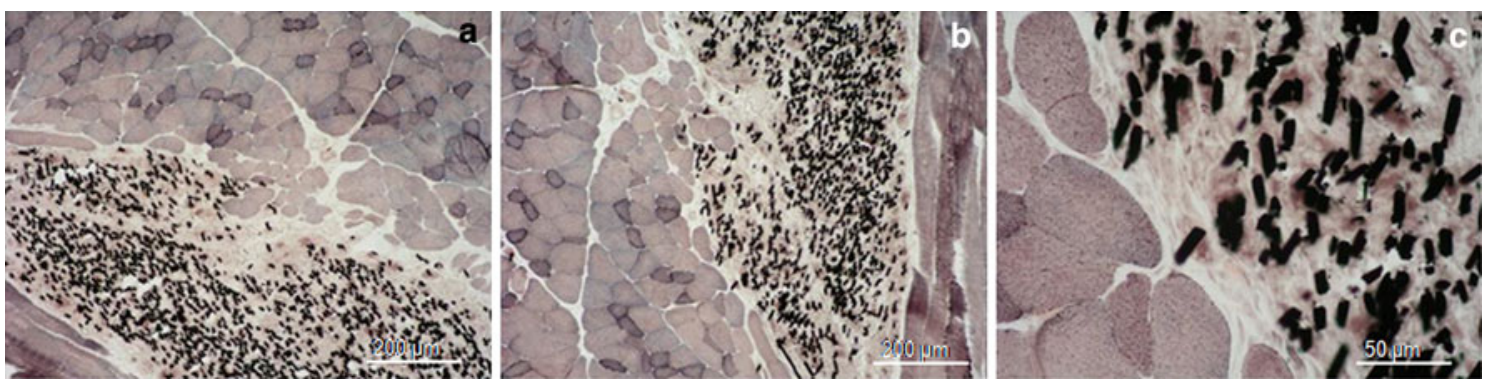

Fig. 14 Cytochrome c oxidase activity on a cross-section of rat skeletal muscle implanted with CF/P fibres a-c after 210 days (obj. 10×, bar $=200 \mu \mathrm{m} ;$ obj. $40 \times$, bar $=50 \mu \mathrm{m})$. Microscope Olympus BX 51, digital camera CAMEDIA

ligament newly developed on a carbon scaffold was morphologically very similar and functionally identical to the replaced natural structure [8]. It has been demonstrated by the later studies that the cellular response to the fibrous carbon material depends on the degree of crystallinity of the material; highly crystalline, high modulus fibers are not suitable for medical purposes, while amorphous fibers are excellent for implants [6]. Grabinski et al. [34] reported that toxicity of carbon materials depends also of dimensions and after $24 \mathrm{~h}$ the carbon nanotubes showed increased cellular toxicity when compared to the carbon fibers and carbon nanofibers. It was also substantiated by Elias et al. [35] for carbon nanofibers obtained by chemical vapor deposition. The average diameter of presented in this paper fibers after carbonization was at the range of $10 \mu \mathrm{m}$. Our results clearly demonstrated the excellent biocompatibility of those carbon fibers, however they also clearly confirmed that biological activity is even more desirable. The lack of bioactivity would result in formation of connective tissue capsule around the implant, as the implanted material would not integrate with the tissue and therefore restricts extensive use of CFs in bone tissue replacement. The presence of HAp on the surface of biomaterial improve its bioactivity. In our study we have proved that by the addition of hydroxyapatite to the spinning solution is possible to obtain effect of modification on the fibers surface. This modification improved the bioactivity as observed from in vitro studies in SBF and which was further also evidenced by better cell adhesion and proliferation. According to in vivo studies the non-sustained inflammatory exudates were observed in case of carbon fibers modified with hydroxyapatite, following proliferation phase. The time of inflammatory was shorter than in case of traditional carbon fibers and the thin connective tissue capsule was formed just after 90 days from implantation, which evidence the proper healing of injury with implanted fibers, so that also fibers biocompatibility (in case of traditional $\mathrm{CF}$ fibers it is observed after 210 days). There are other studies regarding modifications of carbon materials. Liu et al. [36] proved that CNFs modified with $\beta$-TCP possess good biocompatibility and exhibit more favorable properties for cell growth as compared to pure CNFs. Hong-mei et al. [19, 37] have used electrocrystallization process in order to deposit calcium phosphate on the surface of carbon fabrics. By coating carbon fabrics with calcium phosphate they enhanced cell attachment and proliferation. Su-ping et al. [38] mentioned that $\mathrm{CFs}$ after chemical modification can induce calcium phosphate crystal growing on its surface by the process of biomineralization. Modification of PAN spinning solution before coagulation of fibers has rendered successful as HAp particles were observed on the surface of carbon fibers after carbonization process. The proposed approach allows to avoid the post treatment operations, such as chemical modification of fibers or post-treatment by coating with films, which were usually necessary in order to obtain bioactive character of implants. Fibers produced on the proposed way with addition of HAp to the spinning solution are bioactive and biocompatible. However it would be interesting to be able to combine advantages of porous fibers which make them the best from the cells adhesion point of view with advantages of HAp modification which considerably improves bioactivity of CFs.

\section{Conclusions}

On the basis on provided analysis, the following conclusions can be derived:

- $\mathrm{CF} / \mathrm{HAp}$ fibres are bioactive. Modification of the fibres with HAp promotes formation of apatite on the fibre surface during incubation in SBF.

- Analyzed materials did not have cytotoxic effects.

- Modification of fibres with HAp improved the initial adhesion of human osteoblast-like cells on the fibre surface and proliferation of these cells in polystyrene wells at presence of HAp-modified fibres in the cell culture medium. Also the presence of pores in $\mathrm{CF} / \mathrm{P}$ fibres improved proliferation of MG 63 cells.

- After implantation of CFs into rat skeletal muscle in vivo, a direct contact of fibres and surrounding tissues 
indicates good healing of tissues with implanted materials.

- The presence of regenerated fibres indicates that CFs enhance the process of self-reparation of rat skeletal muscle injured during the in vivo implantation.

- All types of the studied CFs stimulated the growth of connective tissue in vivo, manifested by formation of fibrous capsule around the implant. On the other hand, modifications of fibres with pores and HAp accelerated the reduction of the capsule thickness. In $\mathrm{CF} / \mathrm{P}$ and $\mathrm{CF} / \mathrm{HAp}$ fibres, the thickness of connective tissue capsule was reduced effectively after 30 and 90 days from implantation, respectively, while in non-modified fibres, it lasted almost 210 days [39]. Thus, CFs modified with pores or HAp enhance tissue regeneration.

- The process of tissue regeneration in vivo was not disturbed by the presence of the material decomposition products.

- In case of CFs modified with hydroxyapatite also the non-sustained inflammatory exudate was observed. However, the duration of inflammatory response was shorter than in case of traditional CFs. Only a thin connective tissue capsule was formed, which evidenced the proper healing of injury with implanted fibres, and thus biocompatibility of the fibres.

Acknowledgments This work was supported by the Ministry of Science and Higher Education; project POL-POSTDOC III no. PBZ/MNiSW/07/2006/53 (2007-2010) and also by the Grant Agency of the Czech Republic (Grant No. 106/09/1000).

Open Access This article is distributed under the terms of the Creative Commons Attribution Noncommercial License which permits any noncommercial use, distribution, and reproduction in any medium, provided the original author(s) and source are credited.

\section{References}

1. Debnath UK, Fairclough JA, Williams RL. Long-term local effects of carbon fibre in the knee. Knee. 2004;11:259-64.

2. Jenkins DHR, Forster IW, McKibbin B, Ralis ZA. Induction of tendon and ligament formation by carbon implantation. J Bone Joint Surg. 1977;59B:53-7.

3. Pesakova V, Klezl Z, Balik K, Adam M. Biomechanical and biological properties of the implant material carbon-carbon composite covered with pyrolytic carbon. J Mater Sci Mater Med. 2000;11:793-8.

4. Jenkins DHR. The repair of cruciate ligaments with flexible carbon fibre. A longer term study of the induction of new ligaments and of the fate of the implanted carbon. J Bone Joint Surg. 1978;60B(4):520-2.

5. Rohe K, Braun A, Cotta H. Ligament replacement with carbon fibre implants in rabbits light- and transmission electron microscopic studies. Z Orthop Ihre Grenzgeb. 1986;124:569-77.

6. Blazewicz M. Carbon materials in the treatment of soft and hard tissue injuries. Eur Cells Mater. 2001;2:21-9.
7. Czajkowska B, Blazewicz M. Phagocytosis of chemically modified carbon materials. Biomaterials. 1997;18:69-74.

8. Demmer P, Ed FRCS, Glas FRCS, Fowler M, Marino AA. Use of carbon fibre in the reconstruction of knee ligaments. Clin Orthop Relat Res. 1991;271:225-32.

9. Blazewicz M, Paluszkiewicz C. Characterization of biomaterials used for bone regeneration by FTIR spectroscopy. J Mol Struct. 2001;563-564:147-52.

10. Morris DM, Hindman J, Marino AA. Repair of fascial defects in dogs using carbon fibres. J Surg Res. 1998;80:300-3.

11. Kang HJ, Han ChD, Kang ES, Kim NH, Yang WI. An experimental intraarticular implantation of woven carbon fibre pad into osteochondral defect of the femoral condyle in rabbit. Yonsei Med J. 1991;32(2):108-16.

12. Chlopek J, Morawska-Chochol A, Paluszkiewicz C. FTIR evaluation of PLGA-carbon fibres composite behaviour under in vivo conditions. J Mol Struct. 2008;875:101-7.

13. Fujihara K, Huang ZM, Ramakrishna S, Satknanantham K, Hamada H. Feasibility of knitted carbon/PEEK composites for orthopedic bone plates. Biomaterials. 2004;25:3877-85.

14. Blazewicz S, Chlopek J, Litak A, Wajler C, Staszkow E. Experimental study of mechanical properties of composite carbon screws. Biomaterials. 1997;18:437-9.

15. Scotchford CA, Garle MJ, Batchelor J, Bradley J, Grant DM. Use of novel carbon fibre composite material for the femoral stem component of a THR system: in vitro biological assessment. Biomaterials. 2003;24:4871-9.

16. Bokros JC. Carbon biomedical devices. Carbon. 1977;15:355-71.

17. Brooks RA, Jones E, Storer A, Rushton N. Biological evaluation of carbon-fibre-reinforced polybutylenetrephthalate (CFRPBT) employed in a novel acetabular cup. Biomaterials. 2004;25: 3429-38.

18. Cao W, Hench LL. Bioactive materials. Ceram Int. 1996;22: 493-507.

19. Hong-mei H, Philips GJ, Mikhalovsky SV, Lloyd AW. In vitro cytotoxicity assessment of carbon fabric coated with calcium phosphate. New Carbon Mater. 2008;23(2):139-43.

20. Sandeman SR, Jeffery H, Howell CA, Smith M, Mikhalovsky $\mathrm{SV}$. The in vitro corneal biocompatibility of hydroxyapatite coated carbon mesh. Biomaterials. 2009;30:3143-9.

21. Kokubo T. Formation of biologically active bone-like apatite on metals and polymers by biomimetic process. Thermochim Acta. 1996;280(/281):479-90.

22. Hench LL, Splinter RJ, Allen WC, Greenlee TG. Bonding mechanisms at interface of ceramic prosthetic materials. J Biomed Mater Res. 1972;2:117-41.

23. Haberko K, Bucko M, Brzezinska-Miecznik J, Haberko M, Mozgawa W, Panz T, Pyda A, Zarębski J. Natural hydroxyapatite-its behaviour during heat treatment. J Eur Ceram Soc. 2006;26:537-42.

24. Piekarczyk (Rajzer) I, Menaszek E, Zamorska L. Porous carbon fibres for medical applications. Eng Biomater. 2003;30-33:7882.

25. Mikolajczyk T, Bogun M, Blazewicz M, Piekarczyk (Rajzer) I. Effect of spinning conditions on the structure and properties of PAN fibres containing nano-hydroxyapatite. J Appl Polym Sci. 2006;100:2881-8.

26. Rajzer I, Piekarczyk J, Błażewicz M. Study of stabilization of carbon fibres' precursor modified by nanohydroxyapatite. Karbo. 2005;4:265-8.

27. Kokubo T, Takadama H. How useful is SBF bioactivity? Biomaterials. 2006;27(15):2907-15.

28. Sun J, Wei L, Liu X, Li J, Li B, Wang G, Meng F. Influences of ionic dissolution products of dicalcium silicate coating on osteoblastic proliferation, differentiation and gene expression. Acta Biomater. 2009;5(4):1284-93. 
29. Bacáková L, Starý V, Kofronová O, Lisá V. Polishing and coating carbon fibre-reinforced carbon composites with a carbontitanium layer enhances adhesion and growth of osteoblast-like MG63 cells and vascular smooth muscle cells in vitro. J Biomed Mater Res. 2001;54(4):567-78.

30. Czarnowska E, Zajaczkowska A, Godlewski MM, Mroz W, Sobczak JW, Wierzchon T. Combination of hydroxyapatite islets with Ti3P surface layer produced on titanium alloy for bone implants. J Nanosci Nanotechnol. 2009;9(6):3462-8.

31. Bokros JC, Arkins RJ, Shim HS, Houbold AD, Agrawal NK. Carbon in prosthetic devices. In: Deviney ML, O'Grady TM, editors. Petroleum derived carbons. Washington, DC: American Chemical Society; 1976.

32. Adams D, Williams DF. Carbon fiber-reinforced carbon as a potential implant material. J Biomed Res. 1978;12:35-42.

33. Mortier J, Engelhardt M. Foreign body reaction in carbon fiber prosthesis implantation in the knee joint-case report and review of the literature. Z Orthop Ihre Grenzgeb. 2000;138:390-4.

34. Grabinski C, Hussain S, Lafdi K, Braydich-Stolle L, Schlager J. Effect of dimension on biocompatibility of carbon nanomaterials. Carbon. 2007;45:2828-35.
35. Elias KL, Price RL, Webster TJ. Enhanced functions of osteoblast on nanometer diameter carbon fibers. Biomaterials. 2002; 23:3279-87.

36. Liu H, Cai Q, Lian P, Fang Z, Duan S, Ryu S, Yang X, Deng X. The biological properties of carbon nanofibers decorated with $\beta$-tricalcium phosphate nanoparticles. Carbon. 2010;48:2266-72.

37. Hong-mei H, Mikhalovsky SV, Phillips GJ, Lloyd AW. Calcium phosphate sonoelectrodeposition on carbon fabrics and its effect on osteoblast cell viability in vitro. New Carbon Mater. 2007; 22(2):121-5.

38. Su-ping H, Ke-chao Z, Zhi-you L. Preparation and mechanism of calcium phosphate coatings on chemical modified carbon fibers by biomineralization. Trans Nonferr Met Soc China. 2008;18:162-6.

39. Menaszek E, Zamorska L, Zolnierek M, Blazewicz M. Soft tissue response to degradation products of carbon biomaterials - a histochemical study. Eng Biomater. 2003;6(29):23-6. 